\title{
FILME COMO PROPOSTA DE ENSINO E APRENDIZAGEM: O USO DO CINEMA EM AULAS DE LÍNGUA ESTRANGEIRA
}

THE FILM AS A TEACHING AND LEARNING PROPOSAL: THE USE OF MOVIES IN FOREIGN LANGUAGE CLASSROOMS

Elisa Probst Hausmann

\author{
Mestre em Educação pela Universidade Regional de Blumenau (FURB) \\ Professora do Departamento de Letras da Universidade regional de Blumenau (FURB) \\ "Orientadora do Estágio Curricular Supervisionado em Língua Inglesa" \\ E-mail: elisa.furb@gmail.com

\section{Lutiane Schramm Cugik} \\ Graduanda do Curso de Letras pela Universidade Regional de Blumenau (FURB)
}

\section{Odete Ignaczuk}

Graduada em Letras pela Universidade Regional de Blumenau (FURB)

\section{RESUMO}

O presente artigo tem como objetivo analisar e refletir acerca da utilização de filmes como estratégia de ensino e aprendizagem da Língua Estrangeira. Este estudo é integrante das atividades propostas na disciplina de Estágio Supervisionado de Língua Inglesa IV realizada no oitavo semestre do curso de Letras da Universidade Regional de Blumenau (FURB). Neste artigo, são analisadas quatro aulas de uma hora cada, em uma escola de idiomas na cidade de Blumenau - SC. Considera-se a importância deste artigo como objeto de análise que pode contribuir para o aprimoramento de estratégias e métodos de ensino de Língua Estrangeira por meio de filmes legendados em língua estrangeira. Os resultados desta análise indicam que o trabalho com filmes como estratégia de ensino e aprendizagem da Língua Estrangeira pode ser uma importante ferramenta para trabalhar com as habilidades de listening e writing, usando estratégias orais e visuais. As análises assinalam que a motivação foi um fator que influenciou no desempenho dos alunos, pois a estratégia de ensino ora tratada conseguiu aproximar o ensino ao cotidiano e à realidade dos alunos. Aponta-se, então, para a necessidade de constante reflexão dos professores acerca de novas teorias e estratégias de ensino.

Palavras-chave: Filme. Ensino e Aprendizagem de Língua Estrangeira. Ensino de Língua Inglesa. 


\begin{abstract}
This article aims to analyze and reflect on the use of film as a teaching and learning foreign language strategy. This study is a part of the proposed activities in the Supervised Internship discipline of English Language IV held in the eighth semester of Arts and Letters course at the Universidade Regional de Blumenau (FURB). In this article four lessons of one hour each are analyzed, at a language school in the city of Blumenau - SC. The importance of this article is centered on an analysis that can contribute to the improvement of strategies and methods of teaching a foreign language through subtitled films. The results of this analysis indicate that working with films as a teaching and learning foreign language can be an important tool for working with listening skills and writing, using oral and visual strategies, too. The analyzes indicate that the motivation was a factor which influenced the performance of the students because the teaching strategy hereof could approach the teaching to everyday life and reality of students. It is pointed up, then, the need for constant reflection by teachers about new theories and teaching strategies.
\end{abstract}

Keywords: Film. Foreign language teaching and learning. English teaching.

\title{
1 INTRODUÇÃO
}

As pesquisas para encontrar um método de ensino adequado despertam muito interesse no processo de ensino de Língua Estrangeira, o qual é bastante discutido pelos profissionais da área. Devido aos avanços tecnológicos, a comunicação e a informação passaram a ser mais rápidas, assim como o uso de aparelhos como TV, DVD, cinema, Internet, etc. também passaram a fazer parte do cotidiano dos alunos. Todo este desenvolvimento exige que o profissional da educação reflita acerca das estratégias de ensino e aprendizagem, e que envolvam essas tecnologias, favorecendo o estudo de vocabulário e estruturas gramaticais de forma comunicativa.

Nesta perspectiva, o objetivo deste artigo é analisar e refletir acerca da utilização do cinema como estratégia de ensino e aprendizagem da Língua Estrangeira. Este estudo é parte integrante das atividades propostas na disciplina de Estágio Supervisionado de Língua Inglesa IV, realizada no oitavo semestre do curso de Letras da Universidade Regional de Blumenau (FURB). Neste trabalho, são analisadas quatro aulas de uma hora cada, em uma escola de idiomas na cidade de Blumenau - SC. 
Considera-se a importância deste artigo como objeto de análise que pode contribuir para o aprimoramento de estratégias e métodos de ensino de Língua Estrangeira por meio de filmes legendados em inglês. Com isso, esta análise lança um olhar para uma metodologia motivadora que proporcione aos alunos interação em língua estrangeira, com uma linguagem mais real e menos convencional. São apresentados, em seguida, o campo de aplicação do estágio, a fundamentação teórica, a descrição e análise das aulas e, por fim, as considerações finais.

\section{CAMPO DE APLICAÇÃO DO ESTÁGIO}

As aplicações das aulas foram feitas em uma das redes de escolas de idiomas, que funciona desde 2004, situada na cidade de Blumenau, no Estado de Santa Catarina. Conforme os dados encontrados no site da escola, seu objetivo é trazer ao mercado um método atual, moderno e interativo, atendendo ao público infantil, jovem e adulto.

O método da escola contempla ensinar os idiomas Inglês e Espanhol por meio de situações do cotidiano, de forma interativa e dinâmica, fazendo com que os alunos vivenciem, na prática, situações pelas quais podem passar em restaurantes, shopping malls, empresas, universidades, aeroportos, etc.

De 2005 a 2014, consecutivamente, esta rede de escolas recebeu o selo "Rede 05 (cinco) estrelas" pela revista Pequenas Empresas Grandes Negócios. Conquistou também por 6 anos seguidos o Selo de Excelência em Franchising da ABF e foi vencedora por 5 anos do Prêmio Destaque do Selo de Excelência. Devido ao sucesso da marca, a rede já possui mais de 100 escolas, somando mais de 40.000 alunos.

Uma das abordagens utilizadas pela escola é a Abordagem Comunicativa (Communicative Approach), que utiliza-se de situações do dia-a-dia para a comunicação. $\mathrm{O}$ professor trabalha situações que os alunos provavelmente vivenciarão na vida real. O objetivo desta abordagem é trabalhar a competência comunicativa de forma que a gramática seja adquirida naturalmente, dentro dos contextos reais trabalhados ao longo do curso.

Outra abordagem utilizada pela escola é a Abordagem Lexical (Lexical Approach), que foca nos itens lexicais (vocabulário e expressões), trabalhados em contextos diferentes do habitual. Além das aulas regulares com duração de 2 (duas) horas por semana, a escola oferece aulas de Conversation, Listening e Bonus Class.

Os cursos completos, tanto de Língua Inglesa como de Espanhol, têm duração de cinco semestres. Ao final do curso de Língua Inglesa, a escola aplica a prova do TOEIC (exames de proficiência em inglês). Com isso, vale salientar que as aulas aplicadas do estágio ora discutido ocorreram nas aulas de Listening. 


\section{O FILME COMO PROPOSTA DE ENSINO E APRENDIZAGEM}

Nos dias atuais, muito se discute sobre os métodos mais adequados a serem utilizados no ensino e aprendizagem de uma Língua Estrangeira. No ensino de Língua Materna, por exemplo, o professor precisa observar que o aluno já possui alguns conhecimentos prévios acerca da sua língua. Com isso, a função do ensino da Língua Portuguesa é "que o aluno use mais adequadamente e para maior variedade de fins, o conhecimento lingüístico que já possui e foi adquirido antes mesmo de seu ingresso na escola ” (NEGRÃO; SCHER; VIOTTI, 2003, p. 95). Entendemos, com isso, que cabe ao professor levar o conhecimento dos diversos usos da língua que o aluno já é proficiente em seus diferentes contextos. Mas nem sempre as escolas de ensino fundamental e médio trabalham desta forma. Conforme Luft (1985, p. 22, grifos do autor):

Por que os professores em geral não capacitam melhor os alunos para a comunicação oral e escrita? Porque, em vez de fazê-los trabalhar INTENSAMENTE com sua gramática interior, fazendo frases, compondo textos, lendo e escrevendo, pretendem impor-lhes Gramática, teoria e regras. Um ENSINO GRAMATICALISTA abafa justamente os talentos naturais, incute insegurança na linguagem, gera aversão ao estudo do idioma, horror à expressão livre e autêntica de si mesmo.

O fato de, muitas vezes, o professor não considerar o conhecimento que o aluno já traz consigo, o seu repertório comunicativo, faz com que o estudante possa sentir-se inferior no processo de aprendizagem da língua.

No ensino de Línguas Estrangeiras, especificamente a Língua Inglesa, não é diferente. Os alunos, mesmo os que não têm proficiência plena no idioma, já trazem consigo alguns conhecimentos, devido à Internet e aos jogos com os quais interagem, como vocabulário e expressões que circulam nesses meios.

O Inglês parece ser uma das principais línguas de comunicação internacional, e mesmo as pessoas que não são falantes de Inglês geralmente conhecem palavras como: bank, chocolate, computer, hamburger, hospital, hot dog, hotel, piano, radio, restaurant, taxi, telephone, television, university e walkman (HARMER, 2001, p. 1, grifos do autor).

Compreende-se com esta proposição de Harmer (2001), a importância de uma ação comunicativa no ensino da Língua Inglesa. Contudo, entende-se que não é suficiente memorizar vocabulário, listas de verbos e regras gramaticais, para que o aluno consiga entender e fazer-se entendido. Conforme Almeida Filho (1993, p. 15): “O aprender uma língua é [...] aprender a significar nessa nova língua e isso implica entrar em relações com outros numa busca de experiências profundas, válidas, pessoalmente relevantes, capacitadoras de novas compreensões e mobilizadoras para ações subseqüentes." 
Depreende-se que para que o aluno tenha sucesso no aprendizado de uma Língua Estrangeira é necessário, além das competências linguísticas e comunicativas, compreender os diferentes contextos interculturais para conseguir se comunicar de forma adequada com falantes de outras línguas. Neste contexto, apresenta-se o filme como uma proposta de aperfeiçoar o desenvolvimento do processo de ensino e aprendizagem da Língua Estrangeira.

O cinema, com todos os seus recursos tecnológicos para encenar e narrar histórias, pode ser considerado como um recurso lúdico que atrai a atenção dos alunos e os motivam na realização das tarefas propostas pelos professores. Segundo Napolitano (2003, p.11 e 12): "Trabalhar com o cinema na sala de aula é ajudar a escola a reencontrar a cultura ao mesmo tempo cotidiana e elevada, pois o cinema é o campo no qual a estética, o lazer, a ideologia e os valores sociais mais amplos são sintetizados numa mesma obra de arte."

O filme se torna, com isso, um excelente aliado no ensino da Língua Estrangeira, por apresentar uma linguagem autêntica da língua-alvo sem ser modificada para fins didáticos, ou seja, possibilita ao aluno entrar em contato com a língua real utilizada pelos falantes nativos da língua.

O cinema iniciou no fim do século XIX e, no século XX, se tornou muito popular, desenvolvendo paralelamente outros entretenimentos audiovisuais como a televisão, que se tornou um instrumento muito popular de mídia. Com o avanço da tecnologia, as legendas dos filmes, seriados, etc., se tornaram cada vez mais comuns. A TV e o vídeo são vistos como instrumentos pedagógicos considerados eficientes no ensino de Línguas Estrangeiras. Muitos professores acreditam que o uso de filmes ajuda a melhorar as habilidades dos alunos na Língua Estrangeira. Segundo Spanos e Smith (1990), a utilização de filmes consiste em uma inovação em que pessoas de todas as idades são atraídas pela televisão. Com isso, existem muitos programas de TV legendados que podem ser usados conforme os objetivos específicos.

Neste sentido, depreende-se que pode haver um resultado positivo também no que se refere à leitura, já que os alunos precisam ler e compreender com rapidez as legendas dos filmes. Conforme Spanos e Smith (apud SOUSA, 2005, p. 54), os resultados positivos na habilidade de leitura, por conta do uso de filmes legendados, podem acontecer pela associação visual entre palavras e imagens, o desafio para ler e compreender com rapidez as palavras-chave, a observação das diferenças entre legenda e áudio, assim como a diferença entre a língua falada e a escrita. A apresentação simultânea de imagens, oralidade e escrita nos filmes favorece a aquisição de novo vocabulário dentro de um contexto para sua utilização. 
Além dos aspectos positivos já mencionados, é importante mencionar o aspecto motivador no uso dos filmes legendados em sala de aula. As variedades de programas que podem ser utilizados como noticiários, documentários, dramas, filmes, comerciais, programas esportivos e infantis e as diversas variedades de filmes em DVD, são materiais que fazem parte do cotidiano dos alunos. Esses materiais favorecem aos alunos, além do estudo da língua, a aquisição de conhecimentos culturais. Com isso, as aulas podem se tornar mais interessantes e motivadoras.

Neste contexto, Hausmann (1998) considera a definição de Brown (1994, apud FIGUEIREDO, 1993, p. 133) que avalia a motivação como "uma força interior, impulso ou desejo que leva alguém a cumprir determinada tarefa". A autora afirma, ainda, que a motivação acontece devido aos fatores intrínsecos, sendo eles a curiosidade, confiança, interesse por uma atividade, ansiedade, medo, idade e o estágio de desenvolvimento do indivíduo; e aos fatores extrínsecos, como pais, professores e colegas de classe significativos, participativos; elogios e sanções equilibradas; ambiente físico de aprendizagem adequado; contexto educacional e sócio-cultural favorável (WILLIAMS; BURDEN, 1997, p. 137-142 apud HAUSMANN, 1998).

Contudo, é preciso refletir como planejar uma aula com os recursos audiovisuais como filmes em sala de aula, para que se consiga atingir o objetivo de ensino e aprendizagem da Língua Estrangeira. O filme é uma ferramenta que precisa ser pensada por meio de princípios pedagógicos, nos quais o professor possa conduzir discussões de temas presentes no filme escolhido para a aula. Conforme Franco (2004, p. 34), o professor "é um consumidor audiovisual contemporâneo, um espectador especializado, capaz de saciar a curiosidade do aluno em termos das mitologias em relação às mídias". As discussões antes, durante e depois da exibição do filme são importantes para compreensão do aluno sobre o vocabulário e expressões vistas, assim como para incentivá-los a usar o que foi aprendido.

\footnotetext{
A linguagem cinematográfica é exemplar para demonstrar como o processo cognitivo acontece, especialmente para a relação ensino e aprendizagem em sala de aula. Esse processo é a base para um conhecimento que reconhece no outro um compartilhar de sentimentos, afetos, emoções, necessidades vitais, etc., dado justamente o realismo imaginário, que institui a linguagem cinematográfica. É por isso que o cinema, por manipular psicologicamente o espectador, provoca tais processos e pode se constituir, pedagogicamente, em um acionador cognitivo, para consolidar, gramatical e semanticamente, o aprendizado de um idioma que extrapola a mera memorização de palavras e expressões linguísticas. À estrutura gramatical se agrega uma compreensão encarnada, possibilitada pela identificação do espectador com os valores dos personagens (ARAUJO; VOSS, 2009, p. 122, grifos dos autores).
} 
É possível observar, então, que o processo de projeção/identificação possibilita que o aluno entre em contato com cenas e diálogos contextualizados que imitam a realidade e, muitas vezes, a sua própria realidade. Segundo Morin (1997, p. 161), o cinema é "um sistema que tende a integrar o espectador no fluxo do filme" e "o fluxo do filme no fluxo psíquico do espectador".

O cinema pode proporcionar uma visão crítica do mundo, de conhecimentos populares e científicos e até mesmo da mídia. Com isso, é possível trabalhar valores éticos e temas importantes relacionados a experiências que os alunos vivenciam em seu cotidiano, favorecendo a formação de sujeitos autônomos, críticos e éticos. Conforme Vygotsky (2008, p. 145), relacionando o desenvolvimento de aprendizagem da criança entre conceitos científicos, "o aprendizado não se inicia na escola", e sim, no cotidiano. Observa-se, então, que a compreensão de uma língua estrangeira se dá, também, na identificação do aluno com suas experiências, seus desafios, sentimentos e problemas do cotidiano, que por sua vez, envolvem valores morais e éticos. Sendo assim, utilizou-se o cinema como possibilidade de estratégia no ensino e aprendizagem da língua estrangeira.

\section{METODOLOGIA E USO DE FILME EM SALA DE AULA}

Inicialmente, foram planejadas duas aulas utilizando o filme The Devil Wears Prada, um filme americano de 2006, uma adaptação cinematográfica do best seller literário de 2003 de Lauren Weisberger com o mesmo título, dirigido por David Frankel. Pretende-se indicar os procedimentos metodológicos de uma atividade audiovisual, que contemplou aspectos comunicativos, estruturais e valorativos no processo de ensino e aprendizagem da Língua Estrangeira. Aspectos esses que podem contribuir também no processo de formação docente, possibilitando a compreensão da importância da utilização de tecnologias disponíveis atualmente, no processo de aprendizagem dos alunos.

Para a utilização desse recurso, é preciso saber para que e como será utilizado em sala de aula, construindo objetivos para que o filme possa realmente ajudar nos assuntos que serão trabalhados. Para que isso fosse possível, o planejamento teve como objetivo trabalhar vocabulário referente a roupas e adjetivos, articulando com o assunto entrevista de emprego e ambiente de trabalho. Como capacidades1, o objetivo foi trabalhar compreensão auditiva, descrevendo as pessoas, dando opiniões sobre elas. 
Um dos fatores importantes, ainda, para o sucesso da aula, é que o professor conheça os alunos e seus respectivos níveis de conhecimento. Como já mencionado anteriormente, a escola na qual o estágio foi realizado, é particular, e seus alunos possuem interesse em aprender a Língua Estrangeira, seja para viajar ou para trabalho. Os alunos variam entre adolescentes e adultos e possuem níveis diferentes de conhecimento na Língua Estrangeira.

Neste contexto, procurou-se avaliar os assuntos já abordados anteriormente com os alunos, intencionando planejar atividades que os motivassem. A partir das análises para que os alunos pudessem se identificar com os personagens e cenas do filme, as atividades foram preparadas de acordo com o cotidiano, interesses e estilo de vida dos alunos, contemplando novo vocabulário e expressões relevantes aos assuntos, que eram: roupas, descrição de pessoas (adjetivos), entrevista e ambiente de trabalho. Essa estratégia de planejamento teve o objetivo não somente de que os estudantes compreendessem a língua, mas também de que incorporassem vocabulário que fizesse parte de situações conhecidas pelos alunos.

Para dar início à aula, as professoras abriram uma conversa a partir das seguintes perguntas (Figura 1): "Have you ever had a job interview? What kind of clothes do you think you should wear for a job interview? Casual or formal?". As professoras pediram para que os alunos inserissem as expressões: "In my opinion; I believe that; I think that; In my point of view" nas respostas.

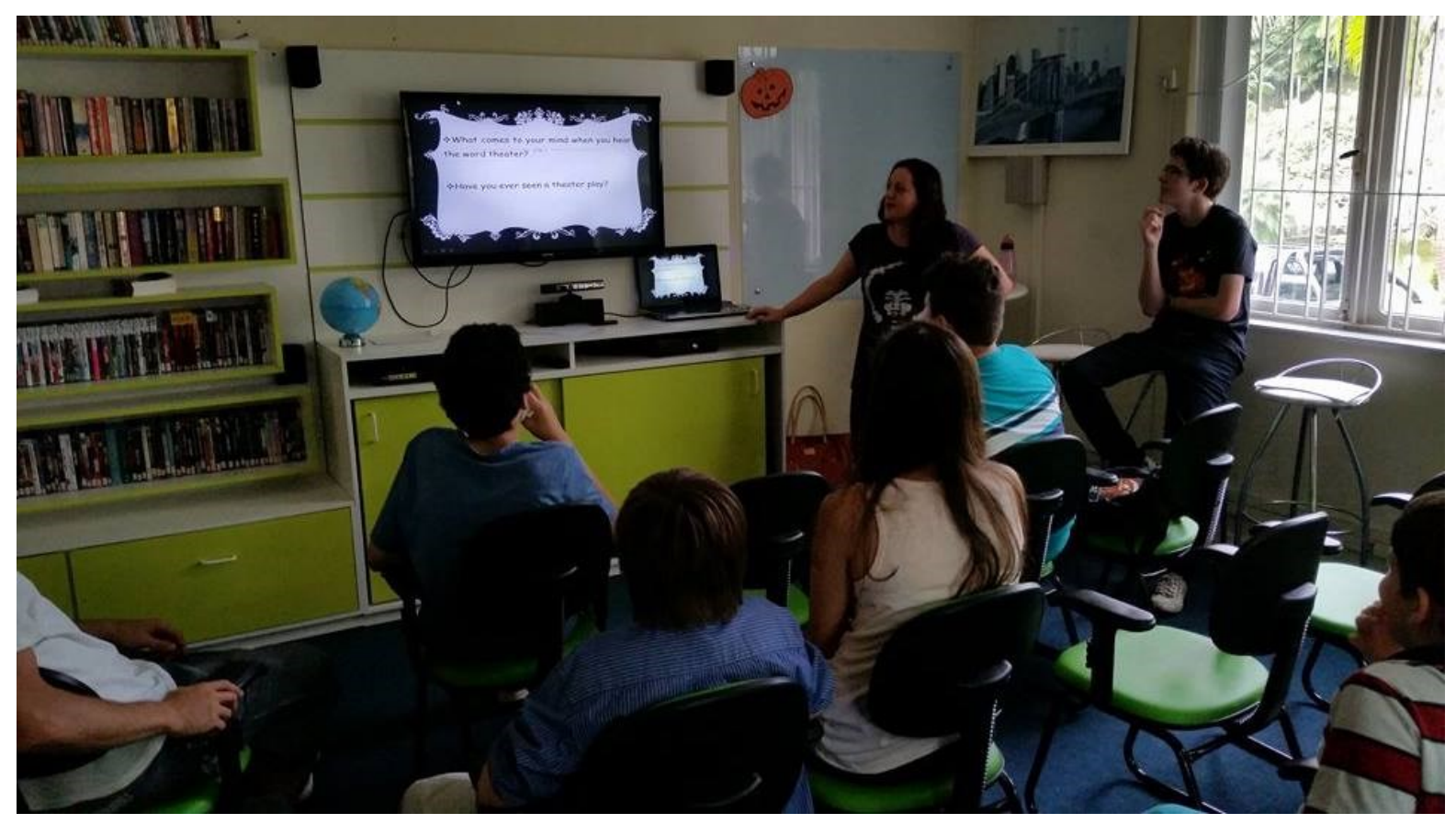

Figura 1: Apresentação do planejamento da aula sobre o filme $O$ diabo veste Prada.

Fonte: arquivo dos autores. 
Os alunos participaram e tiveram êxito na atividade, inserindo as expressões citadas acima, compreendendo o sentido e a utilização de cada uma delas. Em seguida, foi feita uma revisão sobre vocabulário, como roupas e acessórios, momento no qual os alunos puderam relembrar o que sabiam e aprender novas palavras na Língua Inglesa. Após a revisão, foi entregue aos alunos uma pequena atividade na qual deveriam observar o vocabulário que aparece no início do filme (figura 2):

\begin{tabular}{|lll|}
\hline Check what you see in this scene. & \\
$\square$ dresses & $\square$ sneakers & $\square$ fur coat \\
$\square$ skirts & $\square$ gloves & $\square$ caps \\
$\square$ bra & $\square$ coats & $\square$ socks \\
$\square$ panties & $\square$ pullover & $\square$ cosmetics \\
$\square$ handbags & $\square$ stockings & $\square$ vest \\
$\square$ earrings & $\square$ shirt & $\square$ boots \\
$\square$ lipstick & $\square$ T-shirt & $\square$ long overcoats \\
$\square$ mascara & $\square$ blouses & \\
$\square$ scarves & $\square$ eye shadow \\
\hline
\end{tabular}

Figura 2: atividade entregue aos alunos. FONTE: Plano de aula dos autores.

Após a revisão, foi apresentado um excerto do filme, assim como foram, também, descritos os aspectos envolvidos no material catalográfico do mesmo: a ficha técnica, o ano de produção, a direção e o elenco. Os alunos assistiram ao filme e fizeram a atividade proposta. Ao checarem as respostas, as estagiárias observaram que os alunos obtiveram sucesso na atividade, isto é, conseguiram identificar o vocabulário proposto, o que fez com que ficassem mais motivados. As estagiárias mostraram mais uma parte do filme em que os alunos deveriam observar e responder às seguintes questões:

a) In which city does this scene take place?

b) What's the weather like?

c) What kind of transportation does Andy take?

d) Andy is going to have a job interview. Is she well dressed?

e) What should she wear in your opinion? What should she do with her hair?

Figura 3: atividade entregue aos alunos. Fonte: Plano de aula dos autores. 
Todos os alunos conseguiram entender o contexto do filme e das perguntas e responderam às questões (Figura 4).

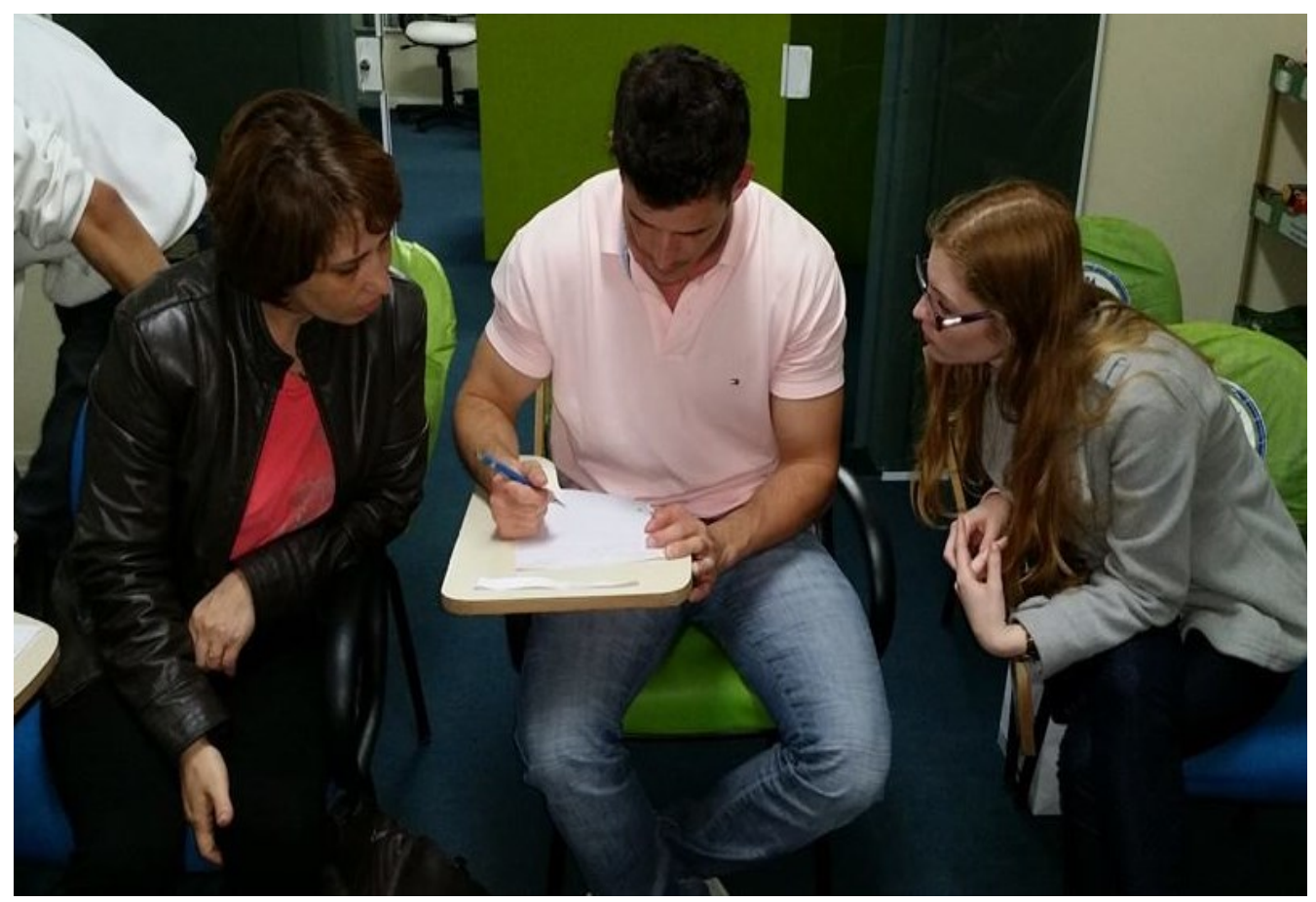

Figura 4: alunos realizando a atividade proposta. FONTE: arquivo dos autores.

Observou-se que os alunos conseguiram entender em que cidade acontecia o filme, o clima e o transporte que a personagem utilizou. O filme traz a moda como um dos principais elementos e verificou-se que houve a compreensão do contexto do filme, por parte dos alunos, em que a personagem fez uma entrevista em uma revista de moda e não estava vestida adequadamente para aquela situação.

Antes de passar para a próxima cena do filme, foi realizada uma conversa com as seguintes perguntas: "How do you feel before a job interview? What should you do before a job interview?". Como os alunos que estavam na aula eram adultos e a maioria trabalhava, quase todos participaram da conversa. Eles já haviam passado por algumas entrevistas de emprego e comentaram que, antes de uma entrevista, seria apropriado pesquisar para conhecer a empresa na qual faria a entrevista. Com isso, conseguiu-se trazer o cotidiano dos estudantes para dentro da sala de aula, fazendo com que a aula fizesse mais sentido e transformando-a em uma prática mais motivadora.

Após a conversa, mais uma parte do filme foi assistida (Figura 5). Nesta parte, trabalhou-se com lugares, profissões e adjetivos, para descrever pessoas. 


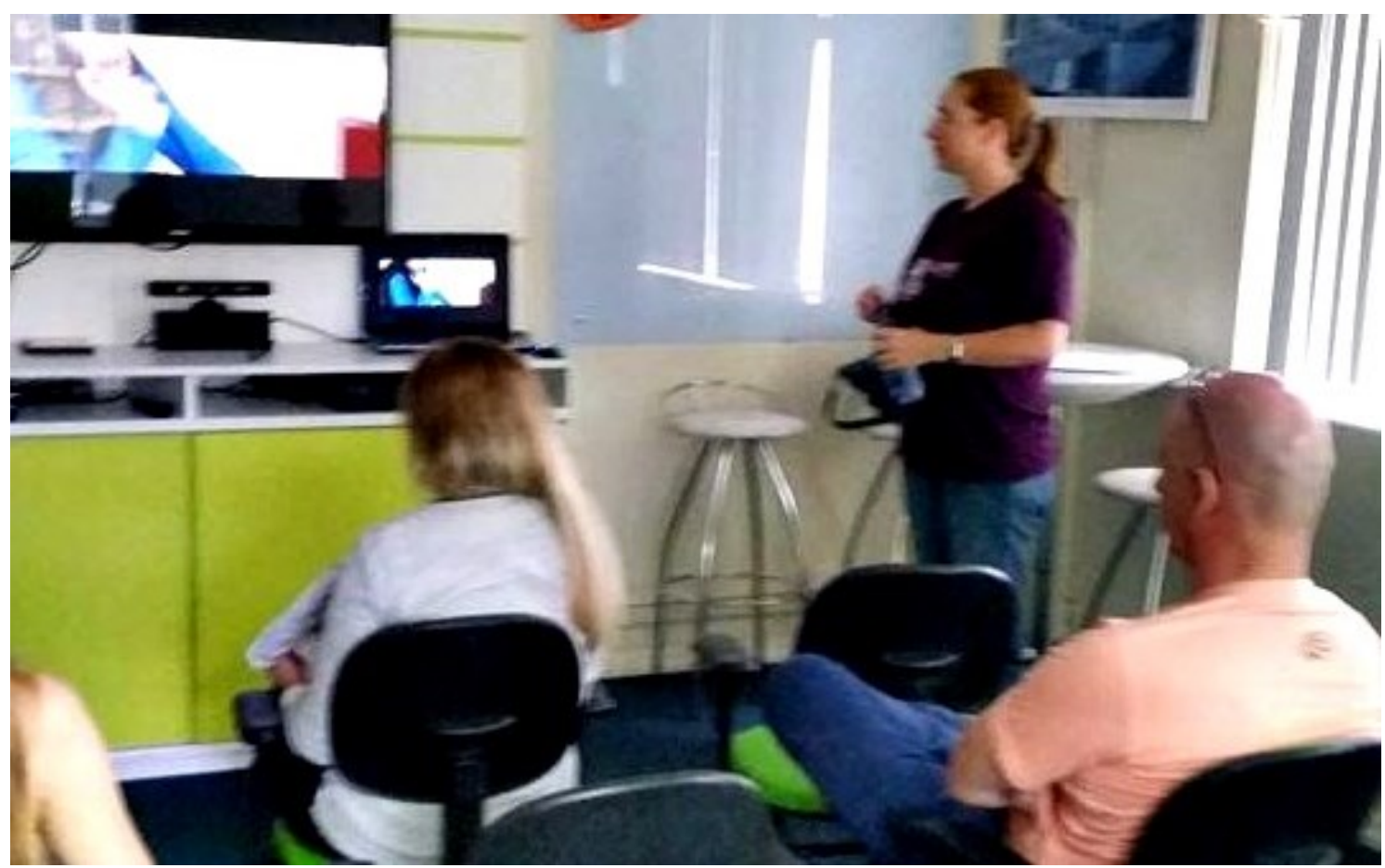

Figura 5: alunos assistem ao filme proposto. FONTE: arquivo dos autores.

Conforme a atividade abaixo (Figura 6), os alunos deveriam identificar o lugar no qual a personagem se encontrava na cena, o tipo de empresa e a profissões dos personagens, assim como alguns adjetivos que eles observaram nas cenas:

Figura 6:atividade entregue aos alunos. Fonte: Plano de aula dos autores. 
Nesta parte, os alunos conseguiram responder a todas as questões, e tiraram dúvidas sobre adjetivos que ainda não conheciam. Então, foi feita uma pequena revisão de alguns adjetivos (Figura 7), discutindo pontos positivos e negativos de cada adjetivo.

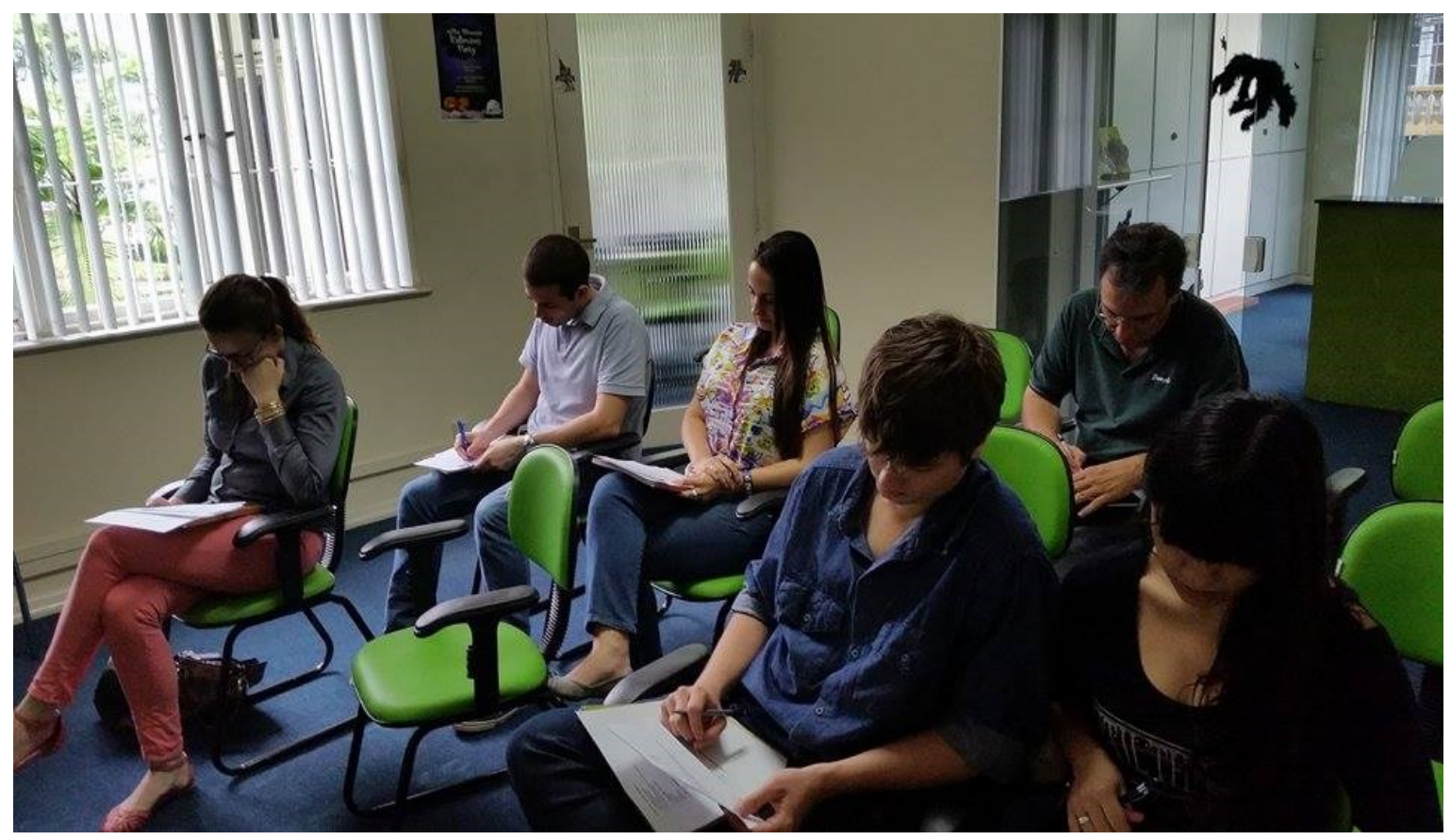

Figura 7: alunos fazendo a atividade proposta. FONTE: arquivo dos autores

Também foi discutido como um chefe deveria se comportar e quais as qualidades que um chefe ideal deveria ter (Figura 8):

Classify the adjectives in the box below in the correct column:

\begin{tabular}{|l|l|l|l|l|}
\hline Hard-working & Humorous & snobbish & critical & Dishonest \\
\hline Polite & Imaginative & ambitious & incompetent & Calm \\
\hline experienced & Suboortive & decisive & generous & Sociable \\
\hline Conceited & Considerate & Well-organized & diolomatic & Punctual \\
\hline Stressed & Respectful & competent & confident & Trustful \\
\hline Helpful & Bossy & ironic & rude & Intimidating \\
\hline
\end{tabular}

\begin{tabular}{|l|l|}
\hline Positive & Negative \\
\hline & \\
& \\
\hline
\end{tabular}

I. What are the characteristics of an ideal boss?

Figura 8: atividade entregue aos alunos. Fonte: Plano de aula dos autores. 
Após a revisão e discussão sobre alguns adjetivos, mais uma parte do filme foi assistida. Pedimos para que os alunos respondessem às seguintes questões: "Can you describe the boss? How does everybody feel about her? Does Miranda want to see Andy? What does she ask Andy about? What does Andy answer?".

Neste momento, o filme apresentava a situação da entrevista. Intentou-se, com esta atividade, trabalhar a compreensão e a produção. Os alunos responderam às questões e conseguiram identificar as falas dos personagens, assim como identificaram como os personagens sentiam-se diante da chefe mostrada no filme.

Para trabalhar com a escrita dos alunos, eles assistiram à mais uma parte do filme. Nesta parte, acontecia uma mudança de estilo de vida da personagem Andy, que passou a se interessar por moda e esquecer seus objetivos iniciais de vida, devido ao comportamento exigente e manipulador da chefe. Com isso, lançaram-se as perguntas: "Does Andy look different? Compare Andy before and after working for Miranda. Do you think a job can change someone's personality?". Os alunos deveriam pensar e escrever suas respostas para compartilhar com os colegas. Todos os alunos responderam às perguntas, tirando suas dúvidas ao formularem as respostas. Após, houve o momento de compartilharem suas respostas e opiniões em conversa, trabalhando, assim, mais uma vez, a oralidade.

Ao encerrar a aula, os alunos elogiaram as atividades, se interessando, inclusive, em assistir ao filme completo. Observou-se, durante e depois da aula, a motivação dos estudantes, pois a atividade fazia parte do cotidiano deles. A tentativa de trabalhar com várias habilidades como listening, writing e speaking, foi alcançada, e em um contexto aproximado da vida real dos alunos.

\section{CONSIDERAÇÕES FINAIS}

Os resultados desta análise indicam que o trabalho com filmes como estratégia de ensino e aprendizagem da Língua Estrangeira, quando usado adequadamente, se torna uma ferramenta importante e útil para o desenvolvimento da proficiência oral e escrita. Nas aulas ministradas, pôde-se trabalhar com listening, writing e speaking. Habilidades essenciais a serem desenvolvidas para se obter a proficiência em uma Língua Estrangeira.

A motivação oferecida pelo uso do filme em sala de aula foi outro fator que influenciou no desempenho dos alunos. A estratégia ora discutida conseguiu trabalhar dentro do cotidiano e de assuntos relevantes aos estudantes, utilizando uma linguagem autêntica, com poucas mudanças para fins didáticos. Com isso, a aula se tornou mais atrativa e os alunos mais interessados em aprender o conteúdo. 
Observou-se que a estratégia de ensino utilizando filmes em sala de aula é dinâmica, pois depende do contexto, dos valores, do cotidiano e da realidade dos alunos envolvidos na aula, fatores em constante movimento. Sobretudo, o cinema pode ser utilizado também para interagir e aprender sobre novas culturas.

Este estágio proporcionou um olhar para a sala de aula que compreende que o ensino da língua estrangeira está além das práticas habitualmente realizadas nas escolas. É necessário, também, proporcionar aos alunos contato com o mundo e suas diversas culturas. Para que isso seja possível, é preciso que o professor esteja em constante reflexão sobre novas teorias e práticas de ensino e aprendizagem.

\section{NOTA}

${ }^{1}$ Neste artigo, usamos o termo capacidades com o sentido de saberes e conhecimentos aplicados.

\section{REFERÊNCIAS}

ALMEIDA FILHO, J. C.P. Dimensões comunicativas no ensino de línguas. Campinas: Pontes, 1993.

ARAUJO, A. R. de.; VOSS, R. de. C. R. Cinema em sala de aula: identificação e projeção no ensino/aprendizagem da Língua Inglesa. Conexão - Comunicação e Cultura. Caxias do Sul, v. 8, n. 15, p. 119-130, jan./jun. 2009.

FRANCO, M. Você sabe o que foi o INCE? In: SETTON, M. da G.J. A cultura da mídia na escola: ensaios sobre cinema e educação. São Paulo: Annablume; ed. da USP, 2004.

HARMER, J. The Practice of English Language Teaching.3.ed. .Essex: Longman, 2001.

HAUSMANN, Elisa Probst. O Problema do uso da Língua Materna em sala de aula de Língua Estrangeira. Dissertação de Mestrado. FURB, Blumenau, SC, 1998.

LUFT, C.P. Língua e Liberdade: por uma nova concepção da língua materna. Porto Alegre: L\&PM, 1985.

MORIN, Edgar. O cinema ou o homem imaginário. Lisboa: Grande Plano, 1997.

NAPOLITANO, M. Como usar o cinema na sala de aula. São Paulo: Contexto, 2003.

NEGRÃO, E.; SCHER, A.; VIOTTI, E. A competência Lingüística. In:FIORIN, J.L. (Org.) Introdução à Lingüística I: objetos teóricos. São Paulo: Contexto, 2003

SIMKA, S. O discurso da inferioridade linguística. Ensino Superior. São Paulo: Segmento, n. 46, julho de 2002. 
SOUZA, Reijane Viana. O uso de legenda oculta (closed captions) e a tradução de filmes: uma atividade prática, dinâmica e criativa. Brasília 2005. Dissertação (Mestrado em Linguística Aplicada) - Departamento de Línguas Estrangeiras e tradução, Universidade de Brasília.

SPANOS, G.; SMITH, J. J. Closed Caption television for adult LEP literacy learners.1990 disponível em: www.wricfacility.net/ericdigests/ed321623.html, acesso em 28.01.04

THE DEVIL WEARS PRADA. Direção de David Frankel. Estados Unidos: Wendy Finerman, 2006. (109 min.), cor.

VYGOTSKY, L. S. Pensamento e linguagem. São Paulo: Martins Fontes, 2008. 